\title{
Groddeck, el símbolo y la bisexualidad ${ }^{1}$
}

Georg Groddeck fue un médico, psicoanalista, literato y filósofo naciḍo el 13 de octubre de 1866 en Bad Kösen. En 1885 inició la carrera de medicina en la Kaiser Universität de Berlín teniendo como profesor a Ernst Schweninger, famoso por ser el médico que había doblegado a Bismarck y que imponiéndole una higiene de vida muy estricta le salvó la vida. Rápidamente Groddeck pasó a formar parte de su pequeño círculo de fieles destacando entre ellos y haciéndose eco de sus ideas. Schweninger no estaba de acuerdo con la medicina académica, no utilizaba medicamentos, sus armas eran la dieta, la hidroterapia, el masaje y su fuerte personalidad, esgrimía un poder absoluto sobre el enfermo y si éste no aceptaba ponerse completamente a sus órdenes y obedecerlo en todo, él no aceptaba cuidarlo. Entendía que el médico no es un científico sino un artista, un creador, y se enfrentaba a la tendencia de la medicina de la época a buscar el mal en los microbios, lo cual convierte al médico en un luchador contra agentes externos en vez de considerarlo un vigilante de la ósmosis sutil entre el ser humano y la naturaleza.

Tras trabajar como asistente de Schweninger se estableció por su cuenta en 1900 abriendo un sanatorio en una villa de Baden-Baden llamada Marienhöhe. Era un caserón de cuatro plantas rodeado de bosques y arroyos, llegaban pacientes con diferentes trastornos orgánicos y se alojaban allí durante una temporada en régimen de pensión completa. Los trataba mediante el masaje, la hidroterapia y la dieta, en consonancia con las enseñanzas que Schweninger le había inculcado. Pero junto a la severidad de éste en Groddeck había lugar para la benevolencia, podía ser muy amable con los enfermos y sobre todo era capaz de ser muy tierno con los que estaban cerca de la muerte.

Pero llegó un momento en que pensó que se había estancado, que no podía llegar más lejos con su forma de trabajar. Entonces apareció la señorita G. Era una solterona que llegó al sanatorio en 1909, padecía diversas enfermedades, tomaba una cantidad enorme de medicamentos y había sufrido varias operaciones, llegaba muy enferma, al borde de la muerte, por lo que la trató con mucho cariño, estuvo charlando con ella, distraídamente, le resultaba muy curiosa la forma en que hablaba y empezó a jugar con la borla del tapete que cubría la cabecera del sillón en el que estaba sentado. De pronto ella cambió por completo, se incorporó y gritando le pidió que dejara la borla en paz, que le molestaba muchísimo. Groddeck la soltó estupefacto. Le preguntó qué otras cosas le molestaban. Ella no podía decírselo hasta que sucediesen, así que siguieron hablando y se dio cuenta de que ella no podía pronunciar determinadas palabras, en ocasiones daba muchos rodeos para referirse a algo, y había objetos cuya presencia no podía soportar siquiera. Así que empezó a interrogarla sobre qué

Rev. Asoc. Esp. Neuropsiq., 2001, vol XXI, n. ${ }^{\circ} 79$, pp. 77-81

' Existen dos libros de Angel Cagigas sobre este autor titulados Georg Groddeck: el soñador de mundos y Genio y figura, ambos publicados en Ediciones del lunar. 
significaban tales objetos para ella y de esta forma se concentró en el estudio del símbolo, que para él significaba la correspondencia entre palabras, objetos o acciones y elementos relacionados con lo sexual. El hombre está dominado por la compulsión a la simbolización, todas nuestras realizaciones, nuestros inventos, nuestras acciones, son símbolos; y la enfermedad también es una expresión del hombre, una más de sus realizaciones, uno de sus símbolos. Esto le daba una salida a su estancamiento, le daba material para trabajar y una nueva visión de la enfermedad que ya no era una prolongación de la de Schweninger sino que era suya propia.

Groddeck siguió trabajando por la senda que había encontrado, tenía éxito con sus enfermos, su trabajo era original... hasta que se dio cuenta del parecido de sus ideas y las de Freud. Así que le escribió una carta haciéndole partícipe de sus planteamientos, sin dejar de señalar que él no establecía diferencia alguna en cuanto a la etiología entre las enfermedades llamadas mentales y las somáticas, simplemente eran diferentes formas de manifestación de una misma realidad, por lo que no había razón para hacer distingos en cuanto al tratamiento, basado siempre en la transferencia y la resistencia. Freud no sólo aceptó sus asertos sino que además le confesó, taimadamente, que no eran originales pues el mismo Ferenczi estaba preparando una serie de trabajos que iban en esa dirección; así que desde ese momento lo reclamaba para su círculo. A partir de entonces trabó relación personal con él y siempre desde un segundo plano que intentaba mantener su independencia pasó a formar parte del círculo de psicoanalistas, detalló sus ideas y las plasmó en gran número de textos que hicieron que Ferenczi le bautizase como el descubridor del psicoanálisis 'in organicis'.

Con su teoria Groddeck afirmaba que la enfermedad tiene un sentido, un significado, queremos expresar algo y no podemos hacerlo por otros cauces así que recurrimos a la enfermedad y no importa que sea corporal o mental, todas son iguales, una expresión de una intención oculta. Esta intención oculta proviene del Ello, concepto que él desarrolló y que fue su creación más original. El Ello es lo que nos hace vivir, la fuerza vital que nos mueve a nosotros y al mundo. Esta fuerza de la que no somos conscientes nos determina, nos vive mientras creemos que somos nosotros quienes vivimos, nos hace ser como somos, necesita expresarse y lo hace a través de nuestro cuerpo y nuestra mente; el Ello se expresa mediante el símbolo y la enfermedad es una de sus formas. El Ello traspasa todas las fronteras $y$ sus procedimientos son idénticos en un suceso mental como el sueño y en un síntoma orgánico, así que la forma de encarar ambos fenómenos y de entenderlos no ha de ser diferente.

Hasta este momento Groddeck había hablado de la infiuencia del símbolo en el síntoma, a partir de entonces trabajó sobre el símbolo como un síntoma más, utilizando las peculiaridades del lenguaje y del arte para probar lo estrechamente ligados que están el símbolo y la vida. Así realizaba una lectura del cuerpo como si éste fuera un texto, letra hecha carne, utilizaba el lenguaje de una forma muy 
rica, sin ninguna restricción, como una herramienta de conocimiento y de trabajo, éste es el uso que del lenguaje debe hacer el médico pues debe desesclerotizar el lenguaje del enfermo petrificado en la enfermedad devolviéndole su plena capacidad de expresión; para eso el médico ha de ser capaz de usar el lenguaje como un artista.

De este modo cerraba un círculo, había empezado estudiando la enfermedad manteniendo que el síntoma es un símbolo, una representación de un proceso interno, ahora trataba las palabras como síntomas proclamándolas instrumentos de interpretación y sustituyendo así el psicoanálisis por la etimología. A través del procedimiento etimológico las palabras se encarnan, se hacen cuerpo vivo informándonos de la historia de la creación del lenguaje como de la creación de un cuerpo, de un microcosmos dotado de sentido. Este estudio del símbolo le. permite comprender asimismo el cuerpo humano como un todo formado por diferentes partes, corazón, tripas, ojos..., donde cada una de ellas se puede estudiar también como un todo; y más allá del cuerpo el símbolo le sirvió para comprender la bisexualidad del ser humano, un ser formado por dos partes, lo masculino y lo femenino, donde la civilización reprime una parte para imponer la otra, escindiendo al individuo en una persona, en una máscara, aunque sin aniquilar la posibilidad de una integración, base de la salud, que puede lograrse asumiendo la dualidad del símbolo.

En 1931 Groddeck escribió un artículo titulado La bisexualidad del ser humano (1). No era la primera vez que se acercaba al tema pero sí la primera que utilizaba este concepto para hacer una crítica del psicoanálisis de Freud. Planteaba que en el estudio de lo inconsciente existen dos fenómenos originarios que revelan el ser humano: su esencia infantil y su bisexualidad; el psicoanálisis se había ocupado del primero pero había soslayado casi totalmente el segundo. Groddeck creía que la bisexualidad del ser humano, aunque era obvia, no había obtenido dentro del psicoanálisis toda la atención que se merece, y aquí deberíamos recordar el revuelo que hacia 1906 levantó el asunto Weininger y que acabó de agriar la relación entre Freud y Fliess.

Groddeck rehusaba toda oposición entre alma y cuerpo, niño y adulto, masculino y femenino, introduciendo así en la teoría analítica uno de sus modelos, el de la bisexualidad. Además pensaba que la bisexualidad no sólo es psíquica sino también física y su simbolismo se percibe en nuestro cuerpo; todo él revela nuestra bisexualidad, también nuestros órganos genitales donde el glande es masculino mientras que el prepucio es femenino, la vagina es femenina mientras que el clítoris es masculino. Ferenczi también había escrito sobre el tema en Masculino y femenino (2) transfiriendo conceptos psicológicos a procesos orgánicos, método que denominó bioanálisis, y hablando del cuerpo como símbolo orgánico; lo cual, como ocurrió en el episodio entre Fliess y Freud, derivó en una discusión con Groddeck por la prioridad en estas ideas, aunque en este caso Ferenczi reconoció la prioridad de Groddeck y las aguas pronto volvieron a su cauce. 
En su artículo Groddeck escribía que en muchas culturas existe el rito de la circuncisión, siempre ligado a la representación de la divinidad, pero ésta es esencialmente bisexual por lo que esta ceremonia se acompaña de otra, una subincisión, una división de la parte inferior del miembro viril que restituye al hombre su bisexualidad. Recordaba que los judíos renunciaban a esta segunda parte de la ceremonia manteniendo sólo la circuncisión, con lo que renunciaban a su similitud divina innata; mediante la circuncisión el judío se convierte sólo en hombre. Creía que no había ningún pueblo en la tierra que fuese tan manifiestamente masculino y que la represión judía de lo femenino había ido tan lejos que se representaban a su divinidad como exclusivamente masculina; esta era la base para su explicación de que el problema de la bisexualidad del ser humano hubiese permanecido marginado en el psicoanálisis. Groddeck criticaba el modo de ser judío porque marginaba una parte del ser humano en cada individuo, aunque no se puede decir que fuese un antisemita; Freud captaba bien la cuestión y por eso toleró a Groddeck en este punto, él podía criticar lo judío porque comprendía la esencia y la problemática del judaísmo, que era la del psicoanálisis. En este sentido el psicoanálisis freudiano juega un papel análogo al del judaísmo, su labor es la de nombrar lo innombrable, se trataría de una obsesión semántica, algo de todo punto contrario al proceder de Groddeck pues a él no le asustaba dejarse ir en lo indefinible. Freud había reconocido mediante el psicoanálisis la bisexualidad fundamental del ser humano y así el carácter arbitrario de toda sesión o reparto de papeles, en consecuencia debía haber puesto en cuestión el pacto que funda y sostiene el edificio social, pero no lo hizo. Este es uno de los sentidos que para Groddeck tiene el problema de la bisexualidad, y su intención a este respecto era eliminar ese reparto de roles, eliminar nuestra sobrestimación por lo masculino que desprecia lo femenino.

Argumentaba que la civilización judeocristina ha impuesto la represión de la bisexualidad en función de una ley divina pero que esto no podía seguir así por mucho tiempo, por eso el estudio de lo inconsciente a la larga había de ser fatal para lo judaico, y pensaba que Freud era muy consciente de esto. Pero es más, la bisexualidad es algo tan reprimido que el Ello para expresarla muy raras veces utiliza lo inconsciente sino que se sirve de vías aún más oscuras que no son accesibles al análisis, se sirve de procesos que se suelen concebir situados más allá del dominio de la psique aunque obviamente esto no deje de ser sólo una clasificación. Se sirve de cualquier particularidad corporal, de la musculatura, la osamenta, la forma de la boca, o de cualquier otra cosa, incluso de órganos internos; así decimos que la boca es un símbolo femenino o la nariz uno masculino, pero la boca es femenina sólo en una posición de reposo, porque revela su bisexualidad en cuanto nos ponemos a hablar, o la nariz es masculina pero sus orificios femeninos, concebimos los órganos sensoriales solamente como receptores pero también son creadores, ya que envían señales que crean percepciones. 
HISTORIA

La bisexualidad del ser humano no es sólo un símbolo mental, algo real por otra parte, sino que además remite a algo tangible. Así se abre una nueva perspectiva para el estudio de cualquier proceso biológico, sea psíquico u orgánico, basado en el símbolo; aunque no es un nuevo campo para él pues hacía años que lo venía trabajando y podemos ver la versión más acabada de sus ideas en el último libro que escribió, El ser humano como símbolo (3), donde el símbolo es el punto nodal que comprende al ser humano, que explica, en la medida de lo posible, al Ello, donde lo orgánico es símbolo de lo psíquico y viceversa, pero no porque sean dos realidades que desde un punto de vista metafórico se puedan superponer sino porque son una misma realidad, la única que existe.

\section{BIBLIOGRAFÍA.}

1. Groddeck, G. Das Zwiegeschlecht des Menschen. Psychoanalytische Bewegung, 1931.

2. Ferenczi, S. Mănnlich und Weiblich. Psychoanalytische Bewegung, 1929.

3. Groddeck, G. Der Mensch als Symbol. Internationale psychoanalytische Verlag, Wien, 1933.

Fecha de recepción: 6/7/01

* Angel Cagigas

Departamento de Psicología

Universidad de Jaén

Paraje de las Lagunillas, $\mathbf{s} / \mathbf{n}$

23071 - JAÉN 